\title{
Formação continuada de professores de matemática com enfoque nas práticas formativas: um estudo das pesquisas acadêmicas
}

\author{
Hilda Ciriaco de Lima ${ }^{1}$ \\ Renata Prenstteter Gama²
}

\section{Resumo}

O artigo apresenta uma pesquisa qualitativa, do tipo estado da arte, que tem por objetivo descrever e analisar práticas formativas identificadas em 44 pesquisas acadêmicas brasileiras (2001-2016), sobre formação continuada do professor de matemática. A análise indica práticas formativas em quatro contextos (Programas/projetos; Oficinas e cursos de curta duração; Cursos de aperfeiçoamento, especialização ou extensão e Grupos), em que se aproximam da concepção de conhecimento-para-a-prática, no entanto, com tendências de inovações relativas ao planejamento conjunto, diagnóstico de necessidades formativas e análise/reflexão de práticas docentes, apoiadas no trabalho colaborativo.

Palavras-chave: Formação continuada; Professores de matemática; Práticas formativas.

Continuing education of mathematics teachers focusing on training practices: a study of academic research

\section{Abstract}

This article presents a qualitative research, state - of - the - art type wich aims to describe and analyze formative practices identified in 44 Brazilian academic researches (2001-2016) on the continuing education of the mathematics teacher. The analysis indicates formative practices in four contexts (Programs / projects, Workshops and short courses, Courses of improvement, specialization or extension and Groups), in which they approach the concept of knowledge-for-practice, however with trends of innovations related to joint planning, diagnosis of training needs and analysis / reflection of teaching practices, supported in the collaborative work.

Keywords: Continuing education; Mathematics teachers; Training practices.

\section{Introdução}

Este trabalho sistematiza as discussões decorrentes das pesquisas acadêmicas brasileiras em Educação Matemática e, dessa forma, procura contribuir com o debate a respeito do professor de matemática e da sua formação continuada. Para isso, a pesquisa procurou responder a questão: "O que as pesquisas sobre formação continuada do professor de matemática evidenciam em relação às práticas formativas"? E apoiou-se no objetivo geral de

\footnotetext{
${ }^{1}$ Universidade Federal de São Carlos. Sorocaba/SP. Endereço eletrônico: hildamatuepg@hotmail.com.

${ }^{2}$ Universidade Federal de São Carlos. São Carlos/SP. Endereço eletrônico: renatapgama@gmail.com.$$
\text { Periódico Horizontes - USF - Itatiba, SP-Brasil - e019013 }
$$ 
descrever e analisar as práticas formativas evidenciadas nas pesquisas sobre formação continuada de professores de matemática.

A formação continuada de professores é preocupação constante dos pesquisadores e isso não difere no caso dos professores que ensinam matemática. Segundo Nacarato (2006), pesquisas nacionais e internacionais revelam que o professor passa a ser considerado como centro das investigações, produtor de saberes e protagonista no processo educativo e a partir disso, surgem mudanças também no foco dos projetos para a sua formação.

A pesquisa de Fiorentini (2002) aponta o distanciamento da concepção de formação contínua daquela sob o enfoque racionalista técnico, baseado em treinamentos, reciclagem ou capacitação de professores, a qual segundo Diniz-Pereira (2008) consiste em instrumentalizar os professores, ou seja, os suprir com um conjunto de técnicas e teorias, para que depois possam ser aplicadas na resolução de problemas práticos. Um dos fatores que levaram a esse distanciamento, segundo Fiorentini e Nacarato (2005) recai sobre estudos realizados na área de formação de professores, os quais indicavam que a formação sob o modelo racionalista técnico se mostrava descontínua em relação à formação inicial, aos saberes experienciais e em relação aos problemas e desafios inerentes à prática escolar, visto que eram ações isoladas, as quais ocorriam em períodos predeterminados e que pouco contribuíam para a mudança nas concepções e práticas dos professores.

Novas perspectivas para a formação de professores, enfatizadas por autores como Imbernón (2010), Nóvoa (2009), Fiorentini e Nacarato (2005), dentre outros, propõem uma formação continuada, na qual a prática docente seja ponto de partida e de chegada, que seja planejada em conjunto com os professores, que considere o contexto das práticas docentes e as relações entre os professores, e que acredite em seu potencial gerador de conhecimentos pedagógicos, que vá ao encontro das necessidades individuais, mas que ao mesmo tempo, seja apoiada no trabalho coletivo.

No entanto, Nóvoa (2009) afirma existir na pesquisa educacional um discurso consensual em torno da aprendizagem docente e ao desenvolvimento profissional, no que se refere à perspectiva de aprendizado ao longo da vida, valorização do professor reflexivo e a importância

$$
\text { Periódico Horizontes - USF - Itatiba, SP-Brasil - e019013 }
$$


do trabalho colaborativo e da investigação sobre a prática. $\mathrm{O}$ autor defende que o necessário para esse discurso ser efetivo na prática é a criação de políticas de formação que valorizem as competências e a autonomia dos professores, defendendo, uma formação construída dentro da própria profissão, onde os professores sejam corresponsáveis pela sua formação e, também, de seus pares, onde reflitam coletivamente e possam ser ouvidos.

Diante destas novas perspectivas, apoiamo-nos em Imbernón (2010, p.10), o qual questiona a formação continuada de professores nos colocando a seguinte indagação: "Quais são as novas ideias e práticas para uma formação de professores em uma nova época"? E responde, em seguida: "devemos olhar para frente. A teoria e a prática da formação, seus planos, suas modalidades e estratégias, seu processo, etc. devem ser introduzidos em novas perspectivas".

Percebemos que olhar para frente, implica olhar para o passado, para o que têm sido feito em relação à formação de professores de matemática, logo nos propusemos a descrever as práticas formativas e analisá-las sob as lentes de três concepções relacionadas às imagens de conhecimento e prática, elaboradas por Cochran-Smith e Lytle (1999), conhecimento (para-aprática, da-prática e na-prática).

Os processos de formação que partem do "conhecimento-para-a-prática", concebem o conhecimento necessário aos professores como "conhecimento formal", constituído pelo domínio da matéria, conhecimento da pedagogia, sobre as bases da Educação, sobre os contextos sociais e culturais da escola, sobre a própria profissão. Partem do pressuposto que esses conhecimentos são produzidos inicialmente na universidade e em seguida devem ser transmitidos por especialistas aos professores para que estes apliquem em suas aulas. Nessa perspectiva, os professores não são geradores de conhecimento e sim usuários e implementadores de teorias construídas por outros.

$\mathrm{Na}$ concepção de "conhecimento-na-prática", os conhecimentos utilizados pelos professores em práticas eficazes de ensino tem fundamentos na experiência da prática, na ação e na reflexão sobre essa ação, logo, é pressuposto que os professores "aprendem quando têm oportunidade de examinar e refletir sobre o conhecimento implícito numa boa prática"

$$
\text { Periódico Horizontes - USF - Itatiba, SP-Brasil - e019013 }
$$


(COCHRAN-SMITH; LYTLE, 1999, p.15). Propostas de formação baseadas nessa concepção tem como ideia central a contribuição de um facilitador, que pode ser um professor experiente, ou um professor da universidade, que em colaboração ajude os professores novatos, ou não, a reorganizarem suas práticas, partindo da análise de situações práticas da sala de aula em busca de resolução para problemas únicos. Aqui o processo de formação ocorre no intercâmbio entre um professor mais experiente e outro menos, ou entre grupos de professores trabalhando em conjunto.

A terceira concepção "conhecimento-da-prática", traz o professor como elemento central e crítico na geração de conhecimentos, a partir da investigação de sua própria sala de aula, difere das demais na medida em que desconsidera a existência de dois conhecimentos distintos, um formal e outro construído na prática, também não distingue professores experientes e novatos. De forma que, o conhecimento é construído coletivamente pelos professores a partir da investigação sistemática de suas práticas e de outros, com ou sem apoio de colaboradores externos ou especialistas. Há uma forte relação entre essa concepção e os processos de mudança e inovação curricular, a responsabilidade sobre o ensino, a liderança e ativismo dos professores.

\section{Procedimentos metodológicos}

A definição do corpus de análise de 44 pesquisas sobre a formação continuada do professor de matemática, do qual este trabalho se refere ocorreu a partir de três momentos.

Um momento inicial contemplou a produção de um mapeamento de pesquisas com o foco na formação continuada do professor que ensina matemática, com o propósito de obter uma visão geral das pesquisas brasileiras produzidas em programas de pós-graduação no país (119 pesquisas selecionadas), a partir da combinação de dois descritores "formação continuada" e "professores que ensinam matemática", a busca se deu em dois bancos de dados, um constante no e-book intitulado "Mapeamento da Pesquisa Acadêmica Brasileira Sobre o Professor que Ensina Matemática: Período 2001 a 2012", sendo este resultado de um projeto de

$$
\text { Periódico Horizontes - USF - Itatiba, SP-Brasil - e019013 }
$$


pesquisa financiado pelo CNPq e coordenado pelo Grupo de Estudos e Pesquisas sobre Formação de Professores de Matemática- GEPFPM, do qual foram selecionadas 76 pesquisas sobre formação continuada do professor que ensina matemática (PEM), no período de 2001 a 2012. E outro constante na Biblioteca Digital Brasileira de Teses e Dissertações (BDTD), que reúne em seu portal teses e dissertações defendidas em todo o país, do qual foram selecionadas 43 pesquisas com o mesmo tema no período de 2013 a 2016. Este momento originou o mapeamento de 119 pesquisas, no período de 2001 a 2016.

Um segundo momento, proporcionado a partir do mapeamento, no qual foi possível identificar um número expressivo de pesquisas sobre a formação continuada de professores que ensinam matemática nos anos finais do Ensino Fundamental e Ensino Médio, ou seja, professores especialistas (58 ao todo), deu origem ao processo de leitura e fichamento, a fim de captar elementos importantes para nossa análise.

No terceiro momento foi realizada a aplicação de um novo critério que contemplasse a nossa questão de investigação, desse modo, selecionamos dentre as 58 pesquisas encontradas, 44 pesquisas em que as práticas formativas foram evidenciadas, se constituindo desse modo, o corpus de análise do qual se trata esse trabalho.

As categorias de análise emergiram do processo de fichamento e possibilitam apresentar as práticas formativas identificadas nas pesquisas sobre a formação continuada do professor de matemática, descrevendo seus contextos. Contextos, entendemos como os âmbitos em que as circunstâncias necessárias ao processo formativo se desenvolvem e as práticas formativas, todas as atividades inseridas nesse processo. Logo, os contextos foram separados em categorias de práticas inseridas em "programas ou projetos", "oficinas e cursos de curta duração", "cursos de aperfeiçoamento, especialização ou extensão", e "práticas de formação inseridas em grupos".

\section{Apresentação dos dados e discussão}

Das 44 pesquisas sobre a formação continuada do professor de matemática identificadas, 16 investigaram práticas formativas no contexto programas ou projetos; em sua maioria (13) 
analisadas em pesquisas de mestrado acadêmico, representando $36 \%$ da produção total. 0 contexto oficinas ou cursos de curta duração, somam $27 \%$, com 12 trabalhos investigados, sendo 8 em mestrados acadêmicos e 4 em mestrados profissionais. Também com 12 trabalhos, o contexto cursos de aperfeiçoamento, especialização ou extensão, foi analisado em 7 pesquisas de mestrados acadêmicos, 3 em mestrados profissionais e 2 em doutorados. No contexto grupos foram identificadas 4 pesquisas que tratam de práticas formativas inseridas somente em grupos, no entanto, identificamos mais 2 que embora, categorizadas como ações inseridas em programas ou projetos conforme seus autores, também se caracterizam como ações inseridas em grupos, sendo 3 doutorados e 3 mestrados acadêmicos.

O quadro a seguir contempla as práticas formativas inseridas em quatro contextos, os quais serão analisados posteriormente segundo suas características, e apresenta seus respectivos percentuais, bem como os autores e o ano de cada pesquisa identificada.

Quadro 1. Contextos de formação

\begin{tabular}{|c|c|c|c|}
\hline CONTEXTO & AUTOR & TOTAL & PERCENTUAL ${ }^{3}$ \\
\hline Programas/Projetos & 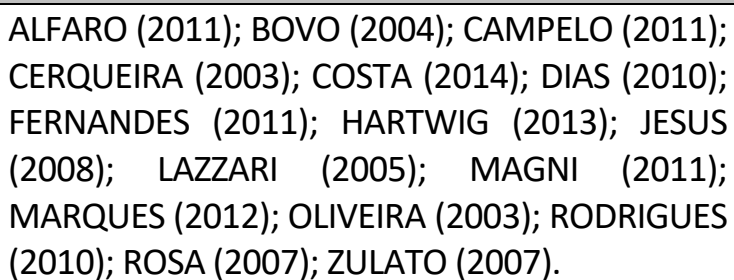 & 16 & $36 \%$ \\
\hline $\begin{array}{l}\text { Oficinas ou cursos de } \\
\text { curta duração }\end{array}$ & $\begin{array}{l}\text { ASSIS (2013); AZEVEDO (2011); COSTA (2005); } \\
\text { DIAS (2005); GOULART (2015); LOPES (2004); } \\
\text { OLIVEIRA (2013); OLIVEIRA (2004); PERES } \\
\text { (2015); SANTOS (2007); SANTOS (2011); } \\
\text { SAVIANO (2011). }\end{array}$ & 12 & $27 \%$ \\
\hline $\begin{array}{l}\text { Cursos } \\
\text { de aperfeiçoamento, } \\
\text { especialização } \\
\text { ou extensão }\end{array}$ & $\begin{array}{l}\text { ARAGÓN (2009); BARBOSA (2014); CARAMORI } \\
\text { (2009); MATTOS (2011); MEDEIROS, A. (2012); } \\
\text { MEDEIROS, L. (2012); OLIVEIRA (2012); } \\
\text { OLIVEIRA (2011); PEREIRA (2015); RIBEIRO } \\
\text { (2005); SILVA (2009); SOUZA (2015). }\end{array}$ & 12 & $27 \%$ \\
\hline Grupos & $\begin{array}{l}\text { FERNANDES (2011); HUANCA (2014); LAZZARI } \\
\text { (2005); KAWASAKI (2007); PERON (2009); } \\
\text { SANAVRIA (2014). }\end{array}$ & 6 & $13,6 \%$ \\
\hline
\end{tabular}

Fonte: as autoras

\footnotetext{
${ }^{3}$ Os percentuais podem divergir, uma vez que dois trabalhos aparecem em dois contextos diferentes.
} Periódico Horizontes - USF - Itatiba, SP-Brasil - e019013 


\section{Ações inseridas no contexto programas ou projetos - características e estratégias de desenvolvimento (16 pesquisas)}

Em relação ao modo de planejamento das ações inseridas em programas/projetos, 8 foram desenvolvidas em parceria entre escola e universidade, ou Secretaria Municipal/Estadual de Educação e universidade, corroborando as pesquisas atuais que defendem a aproximação entre pesquisadores da universidade e professores da escola visando à formação continuada apoiada nas práticas cotidianas e na articulação entre teoria e prática. Segundo Foerste e Lüdke (2003) existem várias concepções de parceria, entre elas, a que decorre da integração da universidade e a escola básica, chamada parceria oficial, a qual é criticada pelos autores por se configurar nos moldes tradicionais, havendo uma clara supremacia dos conhecimentos acadêmicos em detrimento daqueles construídos a partir da experiência dos professores. Em contrapartida, Foerste e Lüdke expõem a parceria colaborativa, emergente de ações reflexivas e com a finalidade de garantir a indissociabilidade teórico-prática nos processos de formação. Na concepção dos autores, tal estilo de parceira é uma prática que favorece a colaboração, a cooperação e a partilha de compromissos e responsabilidades.

Em relação ao modo de planejamento, 9 têm planejamentos abertos. Segundo Crecci e Fiorentini (2013), pesquisas nacionais e internacionais sobre práticas catalisadoras de desenvolvimento profissional, concordam quanto a necessidade da participação plena dos professores, tanto na elaboração de atividades relacionadas ao seu próprio desenvolvimento, quanto em estudos e investigações a partir das demandas, problemas e desafios advindos de seu contexto de trabalho.

Prevalece entre as ações de formação inseridas em programas ou projetos aquelas com tempo de duração de até um ano, no entanto há entre elas quatro formações variando de dois a três anos, o que favorece a aprendizagem ao longo do tempo, superando ações de caráter pontual e temporário. Imbernón (2010) afirma a importância do tempo nos processos de formação, para que os professores analisem as propostas, selecionem as mais adequadas a eles, para então, experimentá-las e incorporá-las em sua prática pedagógica.

$$
\text { Periódico Horizontes - USF - Itatiba, SP-Brasil - e019013 }
$$


Em relação à quantidade de professores atendidos, as formações atendem desde 10 a 50, como as expressas em 8 pesquisas, ou como em 4 delas, mais de 1000 professores, o que é uma característica dos cursos mobilizados pelas Secretarias da Educação dos Estados e Municípios que contemplam a rede toda.

Entre as pesquisas que excederam a 1000 participantes, está a de Rodrigues (2010), que analisou o curso "A Rede Aprende com a Rede", envolvendo 1729 turmas, ou seja, algo em torno de 47 mil docentes da rede estadual, no momento de implantação da Proposta Curricular do Estado de São Paulo: Matemática. Rosa (2007) que investigou o Programa de Educação Continuada - Informática (PEC), sob responsabilidade da SEE/SP através do Núcleo Regional de Tecnologia Educacional (NRTE) envolvendo professores de 91 Diretorias de Ensino do Estado de São Paulo. Cerqueira (2003) que analisou o Projeto desenvolvido pelo Centro de Ciências Exatas e Tecnologia da PUC-SP em parceira com SEE-SP, em que participaram 1800 professores, com ações presenciais e à distância, visando articular a formação continuada e implementação de inovações curriculares. E Dias (2010), que analisou curso online ofertado aos Professores Coordenadores de Matemática de toda a rede pública de São Paulo, estruturado em módulos, onde o objetivo foi o aprofundamento de conceitos e teorias que orientam o Currículo Oficial do Estado de São Paulo. Esse fato corrobora com o exposto por Gatti; Barreto e André (2011), em que os focos da formação continuada nas secretarias estaduais e municipais são orientados para o desenvolvimento do currículo. As autoras percebem esse movimento como um avanço, já que as ações deixam de ser fragmentadas para caminharem no sentido ao cumprimento de expectativas de aprendizagem.

Quanto aos modos de incentivo, observamos um número expressivo de ações desenvolvidas com o apoio de financiamento externo (11), sendo mencionado apoio financeiro do governo federal, através do Ministério da Educação (MEC), Coordenação de Aperfeiçoamento de Pessoal de Nível Superior (CAPES), Ministério da Ciência, Tecnologia, Inovações e Comunicações, através do Conselho Nacional de Desenvolvimento Científico e Tecnológico (CNPq) e instituição filantrópica, como o caso da Fundação Bradesco.

A certificação é mencionada como forma de incentivo e aparece em 9 das pesquisas

$$
\text { Periódico Horizontes - USF - Itatiba, SP-Brasil - e019013 }
$$


identificadas. A questão financeira, de um modo geral, foi pouco abordada nas pesquisas, o que sugere certa falta desse incentivo ao professor no que diz respeito a sua qualificação.

Os cenários de formação foram, a universidade (6 cursos), ainda que em combinação com os demais, o cenário caracterizado como "outros" (6 cursos), os quais são representados por locais próprios de formação como núcleos, diretorias, secretarias, associações etc. e, ambiente virtual de aprendizagem (AVA), 4 dos cursos analisados, cenário que se mostra como alternativa diante de determinadas condições de trabalho, como as excedentes cargas horárias a que são expostos os professores. Segundo Imbernón (2010), o horário inadequado, que sobrecarrega e intensifica o trabalho docente, ainda é um obstáculo a ser superado nos processos de formação.

Dentre as estratégias de desenvolvimento das formações estão os modos de participação dos professores e do pesquisador que analisou o curso. Em $56 \%$ das pesquisas analisadas nesse contexto, o professor participou de forma espontânea, assumindo para si a responsabilidade por seu próprio desenvolvimento. O pesquisador, em mais da metade das pesquisas participou como formador ou organizador da formação, o que confere um alto nível de envolvimento e maior poder de interpretação das ações.

O nível de participação de professores e formadores se refere ao papel que cada participante assumiu na formação. Observamos que desenvolver atividades de modo individual, analisar, discutir ou argumentar sobre as atividades e interagir em ambientes virtuais são as ações mais desempenhadas pelos professores nesse contexto. Enquanto que, aos formadores coube a elaboração da formação, das atividades a serem desenvolvidas e a disponibilização de materiais. E em menor número, a promoção de debates e reflexões acerca das atividades e seus objetivos. Notamos que as tarefas são bem definidas e revelam claramente a posição que cada participante ocupa nas formações.

Os níveis de participação, de professores e formadores, sugerem com base em Imbernón (2010), que tal contexto se aproxima de uma imagem mais instrumental ou de treinamento, onde os "objetivos e os resultados almejados são claramente especificados por alguém e costumam ser propostos em termos de conhecimentos e desenvolvimento de habilidades" (IMBERNÓN, 2010, p.19).

Periódico Horizontes - USF - Itatiba, SP-Brasil - e019013 
De acordo com pressuposições de Cochran-Smith e Lytle (1999), os níveis de participação se aproximam da concepção de aprendizagem de professores identificada como "conhecimentopara-a-prática", cuja base é a ideia de que saber mais (teorias, conteúdos, estratégias etc.), leva a uma prática de ensino mais efetiva, e que revela, por parte do professor, um conhecimento profundo de sua disciplina. Nessa concepção, o conhecimento exemplar dos professores é adquirido nas várias experiências de formação, que dão acesso à base de conhecimento formal, ou seja, ao conhecimento gerado por teorias e descobertas da academia. Nessa perspectiva o conhecimento está voltado para seu uso e o professor é visto como usuário de teorias, mas não gerador, seu trabalho está ligado a resolução de problemas utilizando procedimentos técnicos e não na proposição de problemas baseados em sua experiência profissional. Neste caso, a aprendizagem do professor está centrada no conhecimento que ele tem da matéria e a ênfase recai na necessidade deste aprender uma grande quantidade de conteúdos, estratégias e habilidades. As autoras sugerem ainda que, em programas e projetos impulsionados por esta concepção, o ensino tende a ser transmissivo e a aprendizagem de professores, tende a ser apenas, aquisição de conhecimento.

Estudos teóricos e atividades práticas predominam entre as dinâmicas de desenvolvimento das formações, sendo pouco exploradas pelos professores, ações como produção de material, reelaboração de atividades, registros ou sistematizações e produção de diagnóstico de necessidades formativas, o que, de certo modo, poderiam favorecer um processo mais reflexivo nas formações. O que sugere uma lógica mais pragmática da formação, com ações voltadas à aplicabilidade, ou seja, o formador, conforme Imbernón (2010), seleciona as atividades formadoras que deverão auxiliar os professores a atingirem os objetivos esperados e a estes, cabe a contextualização e transferência para a prática. 0 "objetivo é que o professor desenvolva uma prática coerente com a base de conhecimento e com a metodologia" (COCHRAN-SMITH; LYTLE, 1999, p.12) apresentada.

Em relação ao conteúdo das formações, as metodologias de ensino mais utilizadas se referem a jogos e resolução de problemas, envolvendo vários conteúdos matemáticos, no entanto há presença significativa do conteúdo específico geometria, sendo abordado em 6 dos

$$
\text { Periódico Horizontes - USF - Itatiba, SP-Brasil - e019013 }
$$


trabalhos analisados nesse contexto, representando a preocupação dos pesquisadores em suprir os professores com conceitos desse conteúdo, o qual, conforme Pavanello (1993), volta aos currículos após certo tempo de abandono gerado por reformas educacionais.

\section{Ações inseridas no contexto oficinas ou cursos de curta duraçãos - características e estratégias de desenvolvimento (12 pesquisas)}

Apenas 3 práticas formativas identificadas nesse contexto foram desenvolvidas em parceria entre universidade e escola, ou Secretarias de Educação. Os planejamentos abertos ocorreram em $50 \%$ dos cursos, indicando um maior envolvimento dos professores na elaboração, planejamento e desenvolvimento das formações. O tempo de duração, na maioria, variou entre 20 e 30 horas e atenderam de 10 a 60 participantes.

Em relação aos modos de incentivo, apenas duas pesquisas citaram a certificação. Não houve menção à financiamento externo, concessão de bolsas ou qualquer outro auxílio financeiro.

Nesse contexto, os cenários de formação prevalecem na universidade enquanto lócus, no entanto a escola começa a despontar como possível lugar para as ações formativas, favorecendo o desenvolvimento dos professores, visto que segundo Imbernón (2010), um processo de desenvolvimento profissional docente que atente para a evolução contínua, que valorize seus saberes e considere suas condições e necessidades reais, deve estar conectado ao contexto onde as práticas docentes ocorrem.

Segundo Almeida et al (2011), entre as formações continuadas mais prevalentes em diversas regiões do país, estão aquelas na perspectiva individualizada, a qual busca valorizar o professor, sanando dificuldades ligadas à prática pedagógica, sendo adotada em momentos de mudanças pedagógicas ou implementação de novos programas ou políticas nas Secretarias de Educação (SEs). As autoras apontam que as práticas formativas mais evidentes nessa perspectiva, são os cursos de curta duração (até 60 horas), onde a participação é presencial. Esse formato é justificado pelas Secretarias devido à dificuldade em retirar os professores da sala de

$$
\text { Periódico Horizontes - USF - Itatiba, SP-Brasil - e019013 }
$$


aula para formações de longo período.

As estratégias de desenvolvimento revelam que a participação dos professores em cursos ou oficinas de curta duração foi espontânea em 8 das pesquisas e, em 4 delas, eles tiveram liberação, das escolas ou secretarias, fato que corrobora aos apontamentos de Almeida et al (2011), em que práticas formativas nesse molde, se referem frequentemente, a ações específicas das próprias SEs, para todos os professores, pois geralmente são orientações que devem ser implementadas em sala de aula. Enquanto que, o pesquisador atuou como formador em todas as pesquisas identificadas, assumindo o papel de "assessor externo".

Sobre os papéis de cada participante, observamos que as ações mais evidentes entre os professores foram o desenvolvimento individual de atividades, com análise e discussão sobre elas. Ao passo que, ao formador coube, a elaboração da proposta e disponibilização de materiais. No entanto, novas atribuições ganham destaque, como exemplo, nas pesquisas de Azevedo (2011), Costa (2005), Dias (2005), Oliveira (2013), Santos (2007) e Saviano (2011), em que, a realização de atividades com alunos, troca de experiências, elaboração das próprias atividades e socialização de práticas, ganham sentido a partir da análise e discussão, fato que confere um caráter reflexivo para a formação. Ainda, ao formador coube a promoção de debates e o levantamento de questionamentos, modificando assim a imagem da formação.

As dinâmicas de desenvolvimento mais evidentes neste contexto foram a utilização de softwares e realização de atividades práticas, enquanto que o conteúdo mais abordado foi geometria. Das pesquisas identificadas, 3 delas utilizaram modelagem matemática como ponto de partida para o desenvolvimento da formação.

A análise revela que este contexto se aproxima da concepção abordada por CochranSmith e Lytle (1999), de conhecimento-na-prática. Nesta perspectiva a ênfase está no conhecimento na ação, ou seja, o conhecimento que os professores utilizam para ensinar é manifestado na ação e adquirido a partir da experiência e reflexão dessa experiência. O contexto propício para que ocorra a aprendizagem do professor, neste caso, é o conjunto de professores trabalhando com o objetivo de refletir sobre a prática, onde há a figura do "assessor externo" ou "facilitador", que pode ser um professor da universidade ou um professor mais experiente. Neste

Periódico Horizontes - USF - Itatiba, SP-Brasil - e019013 
contexto, o facilitador se identifica como o próprio pesquisador, o qual foi também o formador. Em iniciativas de desenvolvimento profissional baseadas no conhecimento-na-prática, conforme indicam Cochran-Smith e Lytle (1999), "é fundamental o papel do facilitador, que orienta um grupo no processo de aprender como refletir e/ou conduzir uma investigação sobre a prática" (p.25).

Sobre essas iniciativas, as autoras defendem que:

[...] a questão colocada aos professores é considerar e reconsiderar o que sabem e acreditam, considerar e reconsiderar o que significa saber ou acreditar em algo, e então examinar e reinventar maneiras de ensinar que são coerentes com as crenças e conhecimentos dos professores (COCHRAN-SMITH; LYTLE, 1999, p.25).

Os papéis assumidos por professores e formadores, neste contexto, traduz essa questão. Quando os professores aplicam atividades aos alunos, compartilham suas experiências, analisam e discutem essas atividades, de modo a criar condições para elaborar novas atividades que lhes sejam adequadas. E quando, o formador proporciona debates, reflexões e questionamentos, facilitando, de certa forma, o processo de resignificação das práticas dos professores.

\section{Ações inseridas no contexto cursos de aperfeiçoamento, especilaização ou extensão - características e estratégias de desenvolvimento (12 pesquisas)}

Dentre as doze pesquisas identificadas nesse contexto, 3 foram cursos de aperfeiçoamento - Barbosa (2014), Oliveira (2011), Pereira (2015), 5 de especialização - Medeiros A. (2012), Medeiros L. (2012), Ribeiro (2005), Silva (2009), Souza (2015) e 4 cursos foram de extensão - Aragon (2009), Caramori (2009), Mattos (2011), Oliveira (2012). Apenas três, dos cursos analisados nas pesquisas, foram desenvolvidos em parceria, um devido a um convênio estabelecido entre a SEEDUC e CECIERJ analisado por Barbosa (2014), outro a partir de parceria firmada entre a universidade e Secretaria de Educação investigado por Mattos (2011) e uma parceria entre a UFMS e SED/MS, em curso pesquisado por Oliveira (2012).

$$
\text { Periódico Horizontes - USF - Itatiba, SP-Brasil - e019013 }
$$


As características dos cursos de extensão diferem dos demais, devido a carga horária, que varia de 15 a 40 horas, a estrutura que geralmente é distribuída em vários encontros e quanto aos objetivos, os quais são indicados como, aprimorar e atualizar conhecimentos, visando a superação de possíveis lacunas na formação inicial. Já os cursos de aperfeiçoamento e especialização, convergem entre si, na medida em que são estruturados em disciplinas, módulos ou tópicos, tempo de duração relativamente longo, variando entre 100 e 450 horas, e têm seus objetivos arraigados na instrumentalização dos professores, no que se refere a conteúdos, métodos e técnicas. No entanto, os três tipos de ações formativas se assemelham, no intuito de oportunizar mudanças de atitude e consequentemente de práticas e no fato de serem ofertadas por Instituições de Ensino Superior, cuja participação do professor se dá por motivação própria.

Neste contexto os planejamentos, quase que totalmente foram realizados de forma fechada, ou seja, os organizadores e/ou formadores planejaram, elaboraram e desenvolveram todas as etapas da formação, sugerindo uma forte característica do próprio contexto. Tal contexto possui também, como particularidade, a longa duração dos cursos, sendo que 8 deles variaram entre 160 a 450 horas. O número de participantes é bem divergente, sendo que 6 das pesquisas apresentaram cursos com até 20 participantes e 3 delas tiveram entre 100 e 200 participantes.

Em relação aos modos de incentivo e cenários de formação, a maior parte dos cursos proporciona certificação (8 delas) e o lócus favorável a esse tipo de formação é a universidade, a qual oferta tais cursos, no modo presencial, semipresencial ou totalmente à distância.

Em relação aos cursos de formação ofertados à distância, Gatti, Barreto e André (2011), afirmam que a Universidade Aberta do Brasil (UAB), se tornou um dos principais instrumentos de execução de políticas de formação em nível superior. Indicam ainda, que os cursos de formação continuada correspondem a $51,5 \%$ do total dos cursos ofertados pela UAB, distribuídos em cursos de especialização (mínimo de 360 horas), estes são direcionados a profissionais interessados em aprofundar conhecimentos e aumentar sua qualificação profissional, cursos de aperfeiçoamento (180 horas), visando proporcionar aprimoramento da formação e cursos de extensão (mínimo 30 horas), com a finalidade de ampliação de conhecimentos em determinadas áreas.

$$
\text { Periódico Horizontes - USF - Itatiba, SP-Brasil - e019013 }
$$


Nesse contexto podemos identificar uma mudança nos níveis de participação de professores e formadores, em que a ação mais evidente atribuída aos professores foi o desenvolvimento de atividades com seus próprios alunos, seguida de desenvolvimento de atividades individualmente, análise e discussão sobre tais atividades e elaboração de atividades ou aulas. Ao mesmo tempo em que, as ações do formador, também se expandem, além da elaboração e desenvolvimento da proposta de formação, este disponibiliza materiais e atividades, promove debates, e estabelece tarefas. No entanto, não há indícios de que as novas atribuições proporcionaram uma maior reflexão no processo formativo.

A dinâmica de desenvolvimento das ações formativas nesse contexto, em sua maioria, se apoia em estudos teóricos e utilização de recursos tecnológicos (softwares, planilhas ou calculadoras), já as metodologias de ensino prevalentes foram resolução de problemas e modelagem matemática, envolvendo vários conteúdos, no entanto, há certa ênfase em conteúdos específicos, como é o caso da geometria, aritmética, álgebra e matemática financeira.

As características predominantes identificadas nesse contexto, nos permitem aproximar esse contexto da concepção conhecimento-para-a-prática, a qual segundo CochranSmith e Lytle (1999) tem impulsionado muitos programas voltados à melhoria da formação continuada de professores, processos de mudança escolar e "políticas de licenciamento e certificação". Nesta concepção, o professor "profissional" é considerado capaz de utilizar adequadamente o conhecimento formal em sua prática cotidiana, mas não de produzir conhecimento ou teorias sobre o seu próprio trabalho. As autoras sugerem que os esforços para melhoria das práticas a partir do conhecimento formal estão implícitos em uma visão instrumental ou de treinamento.

Ainda, conforme as autoras supracitadas, o desenvolvimento profissional com base no aprendizado de melhores práticas, também ocorre em propostas de reforma escolar impulsionadas pela concepção conhecimento-para-a-prática, onde organizações não lucrativas ou privadas oferecem treinamento destinado a transmitir aos professores estratégias específicas. Observamos esse fato na pesquisa de Barbosa (2014), que fez parte do corpus de

$$
\text { Periódico Horizontes - USF - Itatiba, SP-Brasil - e019013 }
$$


análise nesse trabalho, cujo curso investigado foi estruturado em tópicos de conteúdos pertinentes ao Currículo Mínimo adotado pelo sistema de ensino estadual.

Entretanto, em meio as 12 pesquisas, existem três que merecem destaque, pois apresentam uma tendência de mudança na imagem de aprendizado de professores. A pesquisa de Aragón (2009), a qual analisou curso de extensão estruturado em encontros, em que houve espaço para discussões, falas individuais e reflexões acerca do ensino de matemática em uma perspectiva sóciocultural. A pesquisa de Silva (2009), que analisou curso de especialização, em que, mesmo estruturado em disciplinas e módulos, permitiu aos professores a escolha do tema de um módulo que se relacionasse às suas necessidades e favoreceu a pesquisa em grupos com apoio da Modelagem Matemática a partir de situações do cotidiano. E Oliveira (2011), que analisou curso de aperfeiçoamento, estruturado em módulos, cuja proposta era de ser desenvolvido em ambiente similar ao que o professor trabalha, ou seja, a sala de aula. Um dos módulos foi permeado de discussões sobre a relação da matemática, questões cotidianas e processos de tomada de decisão.

De modo que, estes últimos representam uma tendência de mudança na perspectiva das práticas formativas nesse contexto, buscando a atuação participante do professor, favorecendo reflexões e articulações acerca do conhecimento matemático, do ensino e das práticas cotidianas, procurando atender as necessidades formativas dos professores, aproximando a formação do contexto das práticas e promovendo maior interação entre os sujeitos, a partir do trabalho coletivo. Indo em busca de uma nova perspectiva para a formação continuada, que conceba o professor de matemática como "sujeito capaz de produzir e (re)significar, a partir da prática, saberes da atividade profissional e de promover seu próprio desenvolvimento profissional" (FIORENTINI; NACARATO, 2005, p.10).

\section{Ações inseridas no contexto grupos - características e estratégias de desenvolvimento (6 pesquisas)}

Das 44 pesquisas analisadas, somente 6 investigaram práticas de formação continuada

$$
\text { Periódico Horizontes - USF - Itatiba, SP-Brasil - e019013 }
$$


no contexto grupos, sendo 4 pertencentes somente à grupos e 2 também inseridas em programas e projetos.

Este contexto de formação nos revela algumas características inovadoras, 5 dentre 6 pesquisas tiveram seus planejamentos desenvolvidos em conjunto, onde professores e formadores decidiram juntos sobre o planejamento e desenvolvimento da formação, dando indícios de uma formação construída dentro da profissão, pelos seus protagonistas, isto significa, "devolver a formação de professores aos professores" (NÓVOA, 2009, p.35).

Das pesquisas identificadas, 3 delas foram em parceria, com tempo de duração variando entre 1 e 3 anos, número reduzido de participantes, na maior parte até 10 professores. Um dos desafios colocados por Day (2001), ao desenvolvimento profissional docente é a questão do tempo, visto que a investigação e reflexão da prática são fatores elementares desse processo, não há como investigar a prática, falar sobre ela sem, no entanto, ter a possibilidade de observála. O autor defende que, oportunidades-relâmpago de formação, não atendem as necessidades intelectuais e motivacionais dos professores, não se relacionam com propósitos essenciais do seu profissionalismo e não atendem as necessidades daqueles que procuram melhorar a qualidade do ensino ofertado aos alunos, especificamente relacionadas à objetivos de mudança e inovação. A quantidade de participantes parece não ser o ponto crítico de tal contexto. Podese falar em trabalhos desenvolvidos em grupo de dois ou três participantes (pesquisador e professor; professor, pesquisador e alunos), ou até mesmo, "diversas pessoas atuando em conjunto" (BOAVIDA; PONTE, 2002, p.3). O que pode se configurar como um complicador neste caso é a variedade de "estatutos profissionais" ou "participantes de instituições diferentes", o que implica gerenciamento das diferenças, a fim de dar conta dos objetivos e necessidades comuns ao grupo.

Em relação aos modos de incentivo, duas pesquisas citaram a certificação dos professores, uma citou auxílio deslocamento e outra, financiamento externo.

Os cenários de formação são diversos, podendo ocorrer na universidade (4), na escola (2), em ambiente virtual (1) ou em locais específicos de formação (1), como diretorias de ensino, núcleos de ensino, secretarias, entre outros, no entanto, a universidade ainda se apresenta como

$$
\text { Periódico Horizontes - USF - Itatiba, SP-Brasil - e019013 }
$$


principal local para formação, mesmo que em combinação com outros cenários.

As estratégias observadas em tal contexto sugerem possíveis mudanças no processo de desenvolvimento das formações docentes, principalmente no que diz respeito ao modo de interação entre professores e formadores. As atribuições dos participantes sofrem transformações, visto que, analisar, discutir e argumentar sobre as atividades; desenvolver atividades com os alunos; bem como elaborar, selecionar, organizar atividades e a formação, passam a ser ações prioritárias, planejadas em conjunto e com a colaboração como estratégia, imprimindo certo grau de investigação sobre a prática. Há expresso um objetivo partilhado o que, conforme Boavida e Ponte (2002), reflete o trabalho colaborativo, visto que neste deve haver um interesse partilhado por todos, um objetivo comum a ser alcançado e maneiras de trabalhar e se relacionar, uns com os outros.

Em relação à dinâmica, tal contexto se apoia em sua totalidade em estudos teóricos, no entanto, utiliza uniformemente outras dinâmicas, não recorrendo a uma única forma de desenvolvimento. Fiorentini (2013), afirma que na perspectiva colaborativa, o conhecimento derivado da pesquisa acadêmica, tem importância fundamental para a compreensão e melhoria da prática, esta passa a ser incorporada criticamente pelos professores, de modo que possam construir seus próprios conhecimentos e teorias em um diálogo entre teoria e prática.

Das 6 pesquisas identificadas, um terço utiliza o diagnóstico de necessidades formativas para balizar o processo de formação, 4 delas trabalha com vários conteúdos da matemática e 2 partem da metodologia de resolução de problemas para desenvolver as ações formativas.

Observamos no contexto "ações inseridas em grupos", uma tendência de mudança na perspectiva de formação continuada de professores de matemática. Visto que, este traz elementos importantes, que há muito tempo, têm sido reivindicados pelos professores e por todos aqueles comprometidos com uma formação ao longo do tempo, que valorize os seus saberes profissionais, que atendam seus clamores, que os fortaleçam em termos de confiança e autonomia.

O nível de participação dos envolvidos sugere que o contexto analisado se aproxima da última concepção identificada por Cochran-Smith e Lytle (1999) como conhecimento-da-prática.

$$
\text { Periódico Horizontes - USF - Itatiba, SP-Brasil - e019013 }
$$


Cuja base é de que os professores têm papel central e crítico na geração de conhecimento sobre a prática, pois suas próprias salas de aula são tomadas como locais de investigação. $\mathrm{O}$ fato dos professores trazerem para a formação elementos de sua prática, com a finalidade de analisá-las conjuntamente com outros, visando a reelaboração e reorganização de práticas ou elaboração de intervenções e a observação de aulas, justificam tal aproximação. As autoras enfatizam que professores e outros, trabalhando juntos geram um conhecimento suplementar de conhecimento formal sobre a prática, sugerem que ao investigarem suas práticas, problematizam seu próprio conhecimento, bem como de outros, "se colocando em uma relação diferente com o conhecimento" (p.29).

A imagem de aprendizado dos professores, a partir dessa concepção, é que a aprendizagem começa com a identificação e a crítica das crenças, pressupostos e experiências particulares, na qual o elemento central é o trabalho de investigação conjunto. O qual gera a colaboração, segundo Cochran-Smith e Lytle (1999).

Em relação à colaboração, os trabalhos identificados no contexto "ações inseridas em grupos" apresentam algumas características particulares, as quais são convenientes de apresentação.

A pesquisa de Fernandes (2011) analisa o surgimento de uma cultura escolar de formação continuada de professores, em que participam de um grupo, alunos de graduação, professores em exercício e professores da universidade, onde juntos tem o objetivo de analisar aulas e atividades e que após discussão do grupo estas são reelaboradas.

Kawasaki (2007) analisou a relação entre mudança e resistência sobre a utilização do computador na prática docente, dentro de um grupo colaborativo, onde participaram alunos de graduação, professores em exercício e professores da universidade.

Peron (2009) investigou a constituição de um trabalho colaborativo em grupo formado por pesquisadora, professora e seus alunos, utilizando a análise da prática e dos erros dos alunos como ponto de partida.

A constituição de um grupo de trabalho colaborativo fez parte dos objetivos da pesquisa de Sanavria (2014), onde participaram cinco professores, mediante inscrição com obtenção de

$$
\text { Periódico Horizontes - USF - Itatiba, SP-Brasil - e019013 }
$$


certificado.

Lazzari (2005), em sua pesquisa buscou compreender como os professores transformam suas práticas, a partir da participação em um grupo de estudos. Os 30 professores participaram de forma voluntária, contaram com liberação da escola, ajuda financeira e certificação. Todos participaram do planejamento das atividades e da escolha dos temas.

As contribuições da ação de formação de multiplicadores foram analisadas por Huanca (2014), em um curso ofertado a 90 professores e destes, 6 professores constituíram um grupo, os quais, posteriormente seriam multiplicadores. O planejamento da formação foi planejado, elaborado e desenvolvido pelo formador. As atividades (problemas de fixação) eram realizadas pelos professores e entregues por escrito, com justificações ou demonstrações ao formador, tais atividades eram discutidas, mas não reelaboradas.

Observamos que há, no contexto analisado, algumas formas de colaboração pertinentes aos processos de formação, os quais, de acordo com Boavida e Ponte (2002) são: trabalho conjunto, relações não hierárquicas, ajuda mútua e objetivos comuns, sem desconsiderar que possam existir objetivos individuais. Ao passo que, os autores indicam que nos processos de formação inseridos em um grupo com forte hierarquização, em que de um lado está aquele que determina as tarefas e de outro, os que executam, configura-se atividade conjunta de natureza não colaborativa. Se aproximando da colegialidade artificial, como exposta por Imbernón (2010), a qual é provocada pela obrigação, imposta e controlada geralmente por um agente externo, de realizar atividades em um projeto coletivo, no entanto, sem alcançar um processo real de colaboração.

A concepção expressa por Cochran-Smith e Lytle, de conhecimento-da-prática traz uma ideia de que professores aprendem colaborativamente em comunidades de investigação, onde a imagem dos professores está ligada a esforços mais amplos de inovação e mudança, em que estes assumem uma postura crítica diante dos próprios conhecimentos e de outros, ao mesmo tempo em que assumem papel de líderes e ativistas. Entretanto, papéis de liderança e ativismo não foram identificados no contexto em questão. 


\section{Considerações finais}

As características gerais dos contextos indicam as parcerias como caminho emergente para formação de professores, representando uma oposição ao modelo em que "os professores deveriam se beneficiar dos conhecimentos produzidos pela universidade" (FERREIRA, 2003, p.33). Ao contrário, eles agora passam a ser vistos como parceiros em um processo conjunto de construção de conhecimentos. As parcerias podem favorecer a aprendizagem em comunidades investigativas e possibilitar que pesquisadores, professores e futuros professores, a partir de uma postura investigativa, trabalhem juntos com a finalidade de transformar o ensino, o aprendizado e a escola, Fiorentini (2013), e Cochran-Smith e Lytle (1999).

Em relação à forma de planejamento, as pesquisas identificadas apontam $50 \%$ planejamentos em conjunto. Imbernón (2010) sugere que uma ação formativa a fim de fomentar o desenvolvimento profissional, deve favorecer o trabalho coletivo voltado para a mudança das práticas, esta se tornaria então em uma "formação a partir de dentro", a qual pode ter características como: atendimento as reais necessidades e "situações problemáticas do coletivo", organização de modo conjunto e resultados que contemplem a todos, e isso será possível quando os professores tiverem a oportunidade de participar de todas as fases do processo de formação.

Sobre a questão financeira, $25 \%$ das pesquisas revelam ações formativas desenvolvidas com apoio financeiro externo, ou seja, com verbas dos governos federal e estadual ou de instituições filantrópicas, o que simboliza o esforço das políticas públicas para o aprimoramento das práticas docentes com a finalidade de atingir maior qualidade de ensino, no entanto, não é suficiente. Nesse sentido, concordamos com Nóvoa (2009, p.21), que as mudanças necessárias ao processo de formação docente, a melhoria das práticas e da qualidade de ensino, não serão obtidas "se não se alterarem as condições existentes nas escolas e as políticas públicas em relação aos professores". Conforme o autor é inútil recorrer a reflexão, reivindicar uma formação colaborativa e propor uma formação com base na investigação e parcerias, se a definição da carreira docente não estiver a favor desse propósito, se não houver organização escolar que as

$$
\text { Periódico Horizontes - USF - Itatiba, SP-Brasil - e019013 }
$$


propiciem.

Porquanto é fundamental que políticas públicas relacionadas a valorização do magistério, condições de trabalho docente e estrutura institucional, sejam colocadas em prática, visto que, segundo Day (2011) essa é uma "responsabilidade conjunta de professores, escola e governo".

A universidade é o cenário de formação continuada mais evidente, no entanto, as formações continuadas em ambiente virtual têm se mostrado como uma alternativa crescente, tanto para preparar os professores a nova realidade tecnológica, quanto como alternativa a falta de tempo, gerada pela carga horária excedente vivenciada por muitos deles. As formações tendo a escola como lócus são tímidas, ainda que pesquisas atuais indiquem a necessidade de se considerar o contexto das práticas docentes nos processos formativos e a importância da escola nesse processo.

Dentre as estratégias, podemos verificar que, partir dos conteúdos específicos da matemática é a estratégia mais utilizada. No entanto, pesquisas como as de Cochran-Smith e Lytle (1999), Fiorentini e Nacarato (2005), entre outras, sugerem que as ações formativas mesmo partindo de conteúdos específicos da matemática e do conhecimento disciplinar do professor, promovam momentos de reflexão e investigação sobre a prática, a qual se relaciona diretamente com tais conteúdos e conhecimentos, que sejam permeados pela criticidade e sistematização e principalmente que atendam às necessidades dos professores.

Entre os conteúdos específicos, há predominância da geometria, indicando a preocupação dos pesquisadores da área da Educação Matemática em suprir os professores com ferramentas que os auxiliem no ensino de uma disciplina que durante muito tempo ocupou lugar secundário na formação dos professores, ocasionando sua ausência na sala de aula.

Duas metodologias para abordagem dos conteúdos específicos se sobressaíram segundo as pesquisas analisadas, Resolução de Problemas, com 7 trabalhos e Modelagem Matemática, aplicada em 6 trabalhos.

Em referência as dinâmicas utilizadas no desenvolvimento das ações, podemos observar algumas inovações, a exemplo as observações de aula, produção de materiais e diagnóstico conjunto de necessidades formativas, elementos que se aproximam da concepção de

$$
\text { Periódico Horizontes - USF - Itatiba, SP-Brasil - e019013 }
$$


conhecimento-da-prática, exposto por Cochran-Smith e Lytlle (1999), no qual a aprendizagem docente ocorre a partir da identificação e a crítica sobre as próprias experiências, crenças e pressupostos, sendo que na investigação da própria prática o "objetivo é a compreensão, a articulação, e ao final a transformação das práticas" (p. 35) com o intuito de promover mudanças na sala de aula.

No entanto, os níveis de participação, que se referem aos papéis assumidos pelos participantes, ainda são bem demarcados. Em $60 \%$ dos 44 trabalhos, dentre as tarefas desempenhadas pelos professores a mais citada foi desenvolver atividades de modo individual, enquanto que ao formador cabe quase que exclusivamente, a elaboração da proposta, bem como das atividades a serem desenvolvidas, é o que revela $93 \%$ das pesquisas analisadas. Fato que corrobora a crítica de Imbernón (2010) sobre o modelo de formação racionalista onde o formador é quem seleciona as atividades que supostamente ajudarão os professores a conquistar os resultados desejados. Logo, os níveis de participação dos envolvidos nas formações sugerem uma concepção próxima ao conhecimento-para-a-prática, em que segundo CochranSmith e Lytle (1999), os professores aprendem quando treinados por um instrutor certificado de algum tipo e em que a ênfase recai sobre aquilo que os professores devem aprender e não no como devem aprender.

Uma tendência de mudança pode ser verificada, a partir das características do contexto grupos, as quais revelam que os níveis de participação dos envolvidos nas ações formativas passam a se fundir, professores tendem a contribuir, tanto na elaboração, quanto no desenvolvimento da proposta de formação, na qual ações como a análise e discussão das atividades a serem desenvolvidas, das experiências e das aulas observadas, ganham outro sentido, quando mediadas pela reflexão, sugerindo uma aproximação ao trabalho colaborativo.

Este nos parece ser um vestígio de mudança, indicando um novo caminho para a formação continuada do professor de matemática, merecendo destaque e olhares mais aprofundados voltados para as efetivas contribuições e implicações para o desenvolvimento docente, bem como, para as situações críticas que podem influenciar tal contexto. 


\section{Referências}

ALFARO, C. F. P. Possibilidades de formação continuada em educação matemática para professores dos anos finais do ensino fundamental: um estudo exploratório. 2011. 166 p. Dissertação (Mestrado Profissional) - UNIFRA, Santa Maria, RS, 2011.

ALMEIDA, P. A. et al. Formação continuada de professores: uma análise das modalidades e das práticas em estados e municípios brasileiros: relatório final. São Paulo: Fundação Victor Civita, 2011.

ARAGÓN, D. T. R. Formação continuada de professores de matemática: espaço de possibilidades para produzir formas de resistência docente. 2009. 111 p. Dissertação (Mestrado em Educação) - UFRGS, Porto Alegre, RS, 2009.

ASSIS, L. Modelagem matemática na formação de professores: algumas contribuições. 2013. 140 p. Dissertação (Mestrado Profissional) - UFOP, Ouro Preto, MG, 2013.

AZEVEDO, M. C. WebQuests na formação continuada de professores de matemática. 2011. 144 p. Dissertação (Mestrado em Ensino das Ciências na Educação Básica) - UNIGRANRIO, Duque de Caxias, RJ, 2011.

BARBOSA, J. L. Uma análise da formação continuada de professores em língua portuguesa e matemática na regional noroeste fluminense. 2014. 126 p. Dissertação (Mestrado Profissional) - UFJF, Juíz de Fora, MG, 2014.

BOAVIDA, A. M.; PONTE, J. P. Investigação colaborativa: potencialidades e problemas. In: GTI (org). Reflectir e investigar sobre a prática profissional. 1a Ed. Lisboa/Portugal: APM, 2002, p.43-55.

BOVO, A. A. Formação de professores de matemática na escola: tensões entre proposta e implementação. 2004. 358 p. Dissertação (Mestrado em Educação Matemática) - UNESP, Rio Claro, SP, 2004.

CAMPELO, N. C. S. Investigando percepções e desvelando reflexões do professor de matemática no processo de continuada. 2011. 147 p. Dissertação (Mestrado em Educação Matemática) - UNIBAN, São Paulo, SP, 2011.

CARAMORI, M. F. O estudo de tópicos de matemática financeira com tecnologias informáticas: opiniões de professores participantes de um grupo de formação continuada. 2009. 110 p. Dissertação (Mestrado Profissional) - UNIFRA, Santa Maria, RS, 2009. 
CERQUEIRA, D. S. Implementação de inovações curriculares no ensino médio e formação continuada de professores: as lições de uma experiência. 2003. 201 p. Dissertação (Mestrado em Educação Matemátia) - PUC, São Paulo, SP, 2003.

COCHRAN-SMITH, M.; LYTLE, S. L. Relationship of knowlwdge and practice: teacher learning in communities. Review of Research in Education. USA, n.24, p.249-305, 1999. Tradução do GEPFPM/Unicamp.

COSTA, J. G. O laboratório de educação matemática na formação continuada do professor de matemática. 2014. 128 p. Dissertação (Mestrado em Educação em Ciências e Matemática) UFG, Goiânia, GO, 2014.

COSTA, R. R. A formação continuada do professor de matemática a partir da sua prática pedagógica. 2005. 121 p. Dissertação (Mestrado em Educação) - PUC, Curitiba, PR, 2005.

CRECCI, V.; FIORENTINI, D. Desenvolvimento profissional docente: um termo guarda-chuva ou um novo sentido à formação. Revista Brasileira sobre Formação Docente. Belo Horizonte, v.5, n.8, p.11-23, jan/jun. 2013.

DAY, C. Desenvolvimento profissional de professores: os desafios da aprendizagem permanente. Porto Editora: Portugal, 2001.não há especificação do número de edição.

DIAS, F. A. S. Formação continuada de educadores: uma investigação sobre interação em um curso para professores de matemática do Ensino Médio. 2010. 182 p. Dissertação (Mestrado em Educação Matemática) - UNIBAN, São Paulo, SP, 2010.

DIAS, M. R. Uma experiência com modelagem matemática na formação continuada de professores. 2005. 121 p. Dissertação (Mestrado em Ensino de Ciências e Educação Matemática) - UEL, Londrina, PR, 2005.

DINIZ-PEREIRA, J. E. A pesquisa dos educadores como estratégia para a construção de modelos críticos de formação docente. In: DINIZ-PEREIRA, J. E.; ZEICHNER, K. M. (Orgs). A pesquisa na formação e no trabalho docente. Belo Horizonte: Autêntica, 2008. p. 11-42.

FERNANDES, R. A. C. Colmeia: ontem e hoje. a construção de uma cultura escolar de formação continuada de professores de matemática no contexto da Universidade Federal de Goiás. 2011. 126 p. Dissertação (Mestrado em Educação) - UFG, Goiânia, GO, 2011.

FERREIRA, A. C. Um olhar retrospectivo sobre a pesquisa brasileira em formação de professores de matemática. In: FIORENTINI, D. (Org). Formação de professores de matemática: explorando novos caminhos com outros olhares. Campinas. Mercado de Letras, 2003. p. 19-41.

$$
\text { Periódico Horizontes - USF - Itatiba, SP-Brasil - e019013 }
$$


FIORENTINI, D. A Investigação em educação matemática desde a perspectiva acadêmica e profissional: desafios e possibilidades de aproximação. Cuadernos de Investigación y Formación in Educación Matemática. Centro de Investigaciones Matemáticas y Metamatemáticas, Universidad de Costa Rica. Año 8, n. 11, dez. 2013. p. 61-82.

FIORENTINI, D. et al. Formação de Professores que Ensinam Matemática: um balanço de 25 anos da pesquisa brasileira. Educação em Revista (dossiê: educação matemática), n. 36. Belo Horizonte: UFMG, 2002. p. 137-160.

FIORENTINI, D.; NACARATO, A. M. (Orgs). Cultura, formação e desenvolvimento profissional de professores que ensinam matemática: investigando e teorizando a partir da prática. São Paulo/ Campinas: Musa Editora/GEPFPM-PRAPEM-FE/UNICAMP, 2005.

FOERSTE, E.; LÜDKE, M. Avaliando experiências concretas de parceria na formação de professores. Revista da Rede de Avaliação Institucional da Educação Superior, v.8, n.4, dez. 2003. p. 163-182.

GATTI, B. A.; BARRETO, E. S. S.; ANDRÉ, M. E. D. A. Políticas docentes no Brasil: um estado da arte. Brasília: UNESCO, 2011.

GOULART, E. B. Formação de professores e modelagem matemática: implicações na prática pedagógica. 2015. 152 p. Dissertação (Mestrado Profissional) - UNIVATES, Lageado, RS, 2015.

HARTWIG, S. C. Formação continuada de professores: um olhar sobre as práticas pedagógicas na construção de conhecimentos geométricos. 2013. 103 p. Dissertação (Mestrado em Educação em Ciências) - FURG, Rio Grande, RS, 2013

HUANCA, R R. H. A resolução de problemas e a modelização matemática no processo de ensinoaprendizagem-avaliação: uma contribuição para a formação continuada do professor de matemática. 2014. 315 p. Tese (Doutorado em Educação Matemática). UNESP, Rio Claro, SP, 2014.

IMBERNÓN, F. Formação continuada de professores. Trad. J. S. Padilha. Porto Alegre: Artmed, 2010.

JESUS, G. B. Construções geométricas: uma alternativa para desenvolver conhecimentos acerca da demonstração em uma formação continuada. 2008. 234 p. Dissertação (Mestrado em Educação Matemática) - PUC, São Paulo, SP, 2008.

KAWASAKI, T. F. Tecnologias na sala de aula de matemática: resistência e mudanças na formação continuada de professores. 2007. 212 p. Tese (Doutorado em Educação) - UFMG, Belo Horizonte, MG, 2007.

$$
\text { Periódico Horizontes - USF - Itatiba, SP-Brasil - e019013 }
$$


LAZZARI, C. A avaliação de uma proposta de formação continuada para professores de matemática do ensino fundamental da rede municipal do estado do Rio Grande do Sul. 2005. 207 p. Dissertação (Mestrado em Ensino de Ciências e Matemática) - ULBRA, Canoas, RS, 2005.

LOPES, A. M. A. Desenvolvimento e pré-testagem de um ambiente virtual construtivista para a formação continuada de professores de matemática do ensino médio. 2004. 150 p. Dissertação (Mestrado em Tecnologia Educacional) - UFRJ, Rio de Janeiro, RJ, 2004.

MAGNI, R. J. M. Formação continuada de professores de matemática: mudanças de concepções sobre o processo de ensino e aprendizagem de geometria. 2011. 181 p. Dissertação (Mestrado em Educação Matemática) - UNIBAN, São Paulo, SP, 2011.

MARQUES, R. N. Formação continuada de professores em uma perspectiva da interação formador-formando. 2012. 116 p. Tese (Doutorado em Educação Escolar) - UNESP, Araraquara, SP, 2012.

MATTOS, S. R. P. Aritmética modular na formação de professores: desenvolvendo o pensamento aritmético e algébrico. 2011. 155 p. Dissertação (Mestrado Ensino de Ciências) UNIGRANRIO, Duque de Caxias, RJ, 2011.

MEDEIROS, A. P. M. Semelhança de triângulos: dos livros do passado à formação continuada de professores via EaD. 2012. 122 p. Dissertação (Mestrado Profissional) - USS, Vassouras, RJ, 2012.

MEDEIROS, L. G. F. Dando movimento à forma: As transformações geométricas no plano na formação continuada a distância de professores de Matemática. 2012. 125 p. Dissertação (Mestrado Profissional) - USS, Vassouras, RJ, 2012.

NACARATO, A. M. A Formação do professor de matemática: pesquisas $x$ políticas públicas. Contexto e Educação. Editora Unijuí, ano 21, n. 75, jan/jun. 2006. p. 131-153.

NÓVOA, A. Professores imagens do futuro presente. Lisboa: Educa, Portugal, 2009.

OLIVEIRA, A. Formação continuada de professores de matemática a distância: estar junto virtual e habitar ambientes virtuais de aprendizagem. 2012. 88 p. Dissertação (Mestrado em Educação Matemática) - UFMS, Campo Grande, MS, 2012.

OLIVEIRA, A. M. P. Formação continuada de professores de matemática e suas percepções sobre as contribuições de um curso. 2003. 192 p. Dissertação (Mestrado Educação Matemática) - UNESP, Rio Claro, SP, 2003.

OLIVEIRA, S. S. Temas regionais de geometria: uma proposta na formação continuada de Periódico Horizontes - USF - Itatiba, SP-Brasil - e019013 
professores de Manaus (AM). 2004. 176 p. Dissertação (Mestrado em Educação Matemática ) UNESP, Rio Claro, SP, 2004.

OLIVEIRA, V. L. P. Vivenciando objetos de aprendizagem na perspectiva da aprendizagem significativa: análise de uma formação continuada desenvolvida com um grupo de professores de matemática de Itatinga (MG). 2013. 302 p. Dissertação (Mestrado em Educação Matemática) - UFOP, Ouro Preto, MG, 2013.

OLIVEIRA, V. C. A. Uma leitura sobre formação continuada de professores de matemática fundamentada em uma categoria da vida cotidiana. 2011. 648 p. Tese (Doutorado em Educação Matemática) - UNESP, Rio Claro, SP, 2011.

PAVANELLO, R. M. O abandono do ensino da geometria no Brasil: causas e consequências. Zetetiké, v.1, n.1, 1993. p. 7-17.

PEREIRA, R. S. G. A educação à distância e a formação continuada de professores de matemática: contribuições de um contexto formativo para a base de conhecimento docente. 2015. 219 p. Tese (Doutorado em Educação) - UNESP, Presidente Prudente, SP, 2015.

PERES, E. M. K. Apropriação de tecnologias digitais: um estudo de caso sobre formação continuada com professores de matemática. 2015. 153 p. Dissertação (Mestrado Profissional) UFRGS, Porto Alegre, RS, 2015.

PERON, L. C. Um processo de pesquisa em colaboração e a formação continuada de professora de matemática a respeito dos erros dos seus alunos. 2009. 239 p. Dissertação (Mestrado em Educação para a Ciência e Matemática) - UEM, Maringá, PR, 2009.

RIBEIRO, R. M. O papel da reflexão sobre a prática no contexto da formação continuada de professores de matemática. 2005. 127 p. Dissertação (Mestrado Educação Matemática) - PUC, São Paulo, SP, 2005.

RODRIGUES, R. M. Os desafios da formação continuada de professores que ensinam matemática no ensino médio em um cenário de reorganização curricular. 2010. 246 p. Dissertação (Mestrado em Educação Matemática) - UNIBAN, São Paulo, SP, 2010.

ROSA, A. P. A formação continuada de professores por meio da utilização de softwares educacionais em um programa de capacitação para o ensino médio, no ano 2002. 2007. 196 p. Dissertação (Mestrado em Educação) - UNISO, Sorocaba, SP, 2002.

SANAVRIA, C. Z. Formação continuada de professores de matemática com enfoque colaborativo: contribuições para o uso reflexivo dos recursos da WEB 2.0 na prática pedagógica. 2014. 285 p. Tese (Doutorado em Educação) - UNESP, Presidente Prudente, SP, 2014.

$$
\text { Periódico Horizontes - USF - Itatiba, SP-Brasil - e019013 }
$$


SANTOS, J. A. Formação continuada de professores EM geometria por meio de uma plataforma de educação à distância: uma experiência com professores de Ensino Médio. 2007. 187 p. Dissertação (Mestrado em Educação Matemática) - PUC, São Paulo, SP, 2007.

SANTOS, R. P. Uma proposta de formação continuada sobre matemática financeira para professores de matemática do ensino médio. 2011. 122 p. Dissertação (Mestrado Profissional) USS, Vassouras, RJ, 2011.

SAVIANO, R. Formação continuada de professores de matemática e o software cabri-géomètre, 2011. 89 p. Dissertação (Mestrado Profissional) - USS, Vassouras, RJ, 2011.

SILVA, M. N. Modelagem matemática na formação continuada: análise das concepções de professores em um curso de especialização. 2009. 160 p. Dissertação (Mestrado em Educação Matemática) - PUC, São Paulo, SP, 2009.

SOUZA, A. S. Design e desenvolvimento de um curso de formação continuada para professores em educação financeira escolar. 2015. 196 p. Dissertação (Mestrado Profissional) - UFJF, Juiz de Fora, MG, 2015.

ZULATO, R. B. A. A natureza da aprendizagem matemática em um ambiente online de formação continuada de professores. 2007. 174 p. Tese (Doutorado em Educação Matemática) - UNESP, Rio Claro, SP, 2007.

Recebido em fevereiro 2018.

Aprovado em maio de 2018.

Periódico Horizontes - USF - Itatiba, SP-Brasil - e019013 